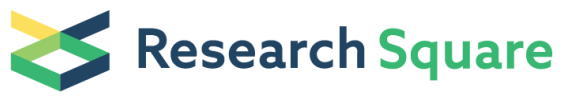 \\ Preprints are preliminary reports that have not undergone peer review. \\ They should not be considered conclusive, used to inform clinical practice, \\ or referenced by the media as validated information.
}

\section{Spatial Variability of Soil Moisture in Mining Subsidence Area of Northwest China}

bai lu

China University of Mining and Technology Beijing Campus

wang yajing

China University of Mining and Technology Beijing Campus

Kai Zhang ( $\nabla$ zhangkai@cumtb.edu.cn)

China University of Mining and Technology - Beijing Campus https://orcid.org/0000-0001-7735-7663

bao kaikai

China University of Mining and Technology Beijing Campus

zhao jiangang

China University of Mining and Technology Beijing Campus

li xiaonan

China University of Mining and Technology Beijing Campus

\section{Research}

Keywords: mining subsidence area, classical statistics and multi-dimensional geo-statistics, spatial distribution of soil moisture, spatial variability, preferential flow

Posted Date: September 21st, 2021

DOI: https://doi.org/10.21203/rs.3.rs-678820/v2

License: @ (i) This work is licensed under a Creative Commons Attribution 4.0 International License. Read Full License 


\section{Abstract}

The current research only investigates the impact of coal mining on deep soil moisture from the perspective of the absolute value of soil moisture. This study applied the combined method of classical statistics and multi-dimensional geo-statistics to analyze the temporal and spatial changes of soil moisture from 0-10m in the mining face of Nalin River No.2 Mine in Northwest China from the perspective of spatial variability. The results of the study showed that in time distribution, on the whole, the soil moisture in the partial areas of the 1-year and the 2-year subsidence area was lower than that in the control area, and the variability increased, but as the subsidence entered a stable period, the degree of variability decreased; vertically observed, in space distribution, the 0-10m soil moisture in the control area had obvious distribution rules with low spatial variability. However, the spatial variability of soil moisture in the 1-year subsidence area and the 2-year subsidence area increased, and the variability showed a trend of increasing continuously with the increase of depth. During the principal component analysis, it was found that the change of soil texture caused by coal mining subsidence, the change of soil pores microstructure caused by geotechnical deformation, as well as the preferential flow caused by changes in groundwater level were the main reasons for the increasing spatial variability of soil moisture. This study revealed the principles of spatial variability of soil moisture in coal mining subsidence areas in Northwest China, which can provide a scientific basis for the restoration of mining areas.

\section{Highlights}

a. In this paper, the combination of classical statistics and multi-dimensional geo-statistics is used to reveal the changes in soil moisture content at different levels in the subsidence area. Compared with the traditional methods, this method is more visualized and reliable to simulate the changes of soil moisture content at different levels in the area, which is more conducive to revealing the changes of soil moisture content in the area.

b. Different from the traditional study of the change of absolute value of soil moisture content in coal mining subsidence area, this paper reveals the change of soil moisture content caused by coal mining from the perspective of spatial variability, and its analysis result is closer to the change law of soil moisture content in subsidence area.

c. Taking the three-dimensional space above and below the well as the research object, this paper analyzes the characteristics of soil water infiltration and migration from the perspective of the causes of preferential flow, reveals the spatial variation mechanism of soil water in coal mining subsidence area, and the analysis results are more comprehensive and objective.

\section{Introduction}

In China's energy structure, coal will still play an irreplaceable role for quite a long time. According to the statistics, by 2030, China's coal consumption will account for about $55 \%$ of primary energy consumption. In the short term, China's energy strategy of "coalbased, diversified development" will not be changed (Wang 2015). The Shen Dong Coalfield is rich in resource reserves that account for about $1 / 4-1 / 3$ of China's total coal reserves (Wang 2017). Therefore, the Shen Dong Coalfield serves as the ballast stone of the coal industry and a stepping stone for China's energy safety and security. The region of Shen Dong is located in the transition zone between the Loess Plateau and the Mu Us Desert, with poor natural conditions and a fragile ecological environment (Wang et al. 2008; Zhang et al. 2012); it is also located in the Yellow River Basin, with the low ecological threshold and poor anti disturbance ability. At present, due to coal mining, the underground water level of the Yellow River Basin is declining and the ecological environment is further deteriorating. In 2019, general secretary Xi Jinping inspected the ecological environment and economic development of the Yellow River Basin and delivered important speeches (Xi 2019), which brought more and more attention to the Shen Dong coalfield located in the Yellow River basin. Therefore, coal exploitation and ecological environment protection in Shen Dong coalfield have always been the focus of research.

In the semi-arid northwestern area with wind and sand, soil moisture is a key factor in restricting the growth of vegetation, and limiting the restoration of the ecological environment in subsided areas caused by coal mining (Dougill et al. 1998; Bi et al. 2014). High-intensity mining causes the movement and deformation of rock formations to form subsidence areas and produce cracks, which affects hydrogeology, soil, and vegetation from the bottom to top (Bi et al. 2014; Wang 2017). The first result is the change in soil moisture caused by the formation of subsidence areas and cracks (Zhao 2006). The transports and changes of soil nutrients are closely related to the changes of soil moisture, so changes of soil moisture in subsidence areas will inevitably lead to the transports and changes of nutrients such as nitrogen, phosphorus, potassium and organic matters (Li et al. 2001; Cheng et al. 2014; Liu et al. 
2014). The changes of soil moisture also vary the distribution and circulation of the original water and material in the ecosystem, thus affecting the ecological environment. Therefore, it is of great significance to study the change law and influence mechanism of soil water under the condition of coal mining subsidence for vegetation restoration and ecological reconstruction in coal mining subsidence areas.

On the one hand, some scholars believe that ground fractures caused by coal mining are important factors in affecting the changes of soil moisture in subsidence areas (Wei et al. 2006; Wang et al. 2011; Liu et al. 2016; Guo et al. 2019). In addition, the depth, density, width as well as distance from the fractures all influence the changes in soil moisture (Zou et al. 2014; Zhang et al. 2015; Ma and Yang 2019; Wu et al. 2019; Wu et al. 2020). Zhang et al. (2015) tracked and monitored the fractures in a fixed position in Bu Lian ta mine in Shen fu-Dongsheng Coalfield, and then found that the soil water content in the fractured and non-fractured areas within the subsidence area was less than that in the virgin area. Moreover, the soil water content around the ground fractures decreased significantly, with a significant downward trend in the depth of 0-90 cm, ranging from 9.27-15.47\%; Wu et al. (2019) took the Fuxin subsidence area as the example to extend their research, finding that with the increase of the distance from the crack, the soil moisture content increased, but the influence was not obvious after 2m; Ma and Yang (2019) took the soil in the development area of ground fractures mined by Ephedra in northern Shanxi as the research object, finding that the moisture content of the soil near stepped ground fissures, except the surface, is higher than that in the non-cracked area at all depths. The above scholars believe that the ground fissures caused by coal mining are important factors in affecting the changes of soil moisture in the subsidence area.

On the other hand, some scholars believe that coal mining subsidence has no or unobvious effect on soil moisture. For example, Wang et al. (2006) studied the soil bulk density, porosity, saturated hydraulic conductivity in the subsided and non-subsided areas of the Bu Lian ta Coal Mine. The study discovered that the soil bulk density and porosity of the top and middle of the collapsed dune did not have significant changes while the soil bulk density at the bottom of the dunes and the lowlands between the dunes was significantly reduced with the significantly increased porosity. Additionally, the saturated hydraulic conductivity within $0-60 \mathrm{~cm}$ did not change significantly. However, the research results of "ecological restoration technology experiment and demonstration research in Shen Dong mining subsidence area" completed by Inner Mongolia Agricultural University and China University of Mining and Technology in 2007 show that basically, coal mining subsidence does not affect soil nutrients and moisture (Li et al. 2012). The scholars who hold the above views believe that the soil water supply comes from atmospheric precipitation, but not from groundwater. Mining disturbance affects groundwater, but has a limited impact on soil water. Therefore, according to previous studies, there is no unified understanding of whether coal mining causes soil moisture change in subsidence area, which needs to be further studied.

To sum up, the authors believe that from a macro point of view, surface cracking and collapse affect the conditions of soil water infiltration and evaporation, thus resulting in the change of soil water; from a micro point of view, the factors affecting the change of soil texture, bulk density and pore structure will also cause the changes of soil moisture (Zhao et al. 2010). But the main reason for the differences in previous studies is that the influence of coal mining on soil moisture was only studied from the absolute value of soil moisture, while ignoring the characteristics of the soil itself as a heterogeneous continuum. Even at the same time, there will be obvious differences in soil characteristics at different spatial locations, that is, spatial variability. As one of the important parameters of soil physical properties, soil moisture has high spatial variability. At present, scholars in China and other countries mainly focus on the change of absolute value of soil moisture in subsidence area, but there is little research on the spatial variation of soil moisture in aeration zone in subsidence area.

Therefore, the study takes Nalin River No.2 mine in the east of Mu Us Desert as the research object. Through the construction of classical statistics combined with multi-dimensional geo-statistics method, this paper analyzes the variability of soil moisture in the unsaturated zone in the subsidence area from the perspectives of time and space, and discusses the impact of coal mining subsidence on soil water in the aeration zone from the perspective of spatial variability rather than that of absolute soil water changes, so as to provide the scientific basis for ecological restoration in mining areas.

\section{Materials And Methods}

\subsection{Overview of the study area}


In the east of Mu Us Desert (108 $51^{\prime} 30^{\prime} \mathrm{E}-109^{\circ} 00^{\prime} 00^{\prime} \mathrm{E}, 37^{\circ} 58^{\prime} 00$ "N - $\left.38^{\circ} 05^{\prime} 30^{\prime} \mathrm{N}\right)$, Nalin River No.2 mine is located in the ecologically fragile northwest region. The geographical location is shown in Fig. 1 . The region has an arid and semi-arid continental climate, dry and rainless, windy and sandy. The average annual precipitation is $350 \mathrm{~mm}$ and the average annual evaporation is $2500 \mathrm{~mm}$ here. At the same time, the region is located in the semi-desert area of plateau desert landform, with sparse and scattered vegetation and crescent or wavy dunes on the surface. The soil types are mainly fixed and semi-fixed aeolian sandy soil, and the vegetation types are mainly xerophytic and semi-xerophytic sandy. There are two seasonal rivers in the area, the depth of the phreatic water is $19.15-25.65 \mathrm{~m}$. Furthermore, the average buried depth of the main coal seam is about $602 \mathrm{~m}$, and the average thickness is about $4.65 \mathrm{~m}$. The mining method is longwall combined mining.

\subsection{Collection and determination of soil samples}

According to the time of the mining completion, the study area was divided into control area (CK), 1-year subsidence area (S1) and 2year subsidence area (S2) with partition sampling. According to the underground coal mining process, the checkerboard distribution method was adopted. The grid design was $75 \mathrm{~m} * 100 \mathrm{~m}$, and each sampling point was in the center of the grid. The focus was on the subsidence basin areas and edge fracture development areas such as the edge and center line of the working face. A total of 60 soil sample collection points were set up in three areas, among them 12 were set in the control area, and 24 were respectively arranged in one-year subsidence area and two-year settlement area, as shown in Fig. 2. Using soil drill, 0-10m soil samples were collected at each sampling point, with an interval of $1 \mathrm{~m}$. Three composite samples were randomly collected from each layer of soil depth, so totally 1,800 soil samples were collected from 60 sampling points. After natural drying, the samples were sieved with $2 \mathrm{~mm}$ mesh for the measure of soil moisture (SM). SM was measured by gravimetry, in which each fresh soil sample was dried at $105^{\circ} \mathrm{C}$ for 8 hours so that SM was generated by the difference between the fresh weight and dry weight of soil (Zou et al. 2014).

\subsection{Data analysis}

\subsubsection{Classical statistical methods}

SPSS20.0 data analysis tool was used to conduct normal distribution K-S test on all data $(p=0.05)$, and the mean, median value, standard deviation (SD), coefficient of variation (CV), maximum value and minimum value were calculated. Mean and median values reflect the centralized trend of samples, while the positional relationship between mean and median values reflects the relationship between data distribution and outliers. The SD and CV reflect the variability characteristics of data so as to measure the degree of data dispersion (Wu et al. 2019). It is generally recognized that CV $>40 \%$ is high variation, $10 \%<\mathrm{CV}<40 \%$ is moderate variation, and $\mathrm{CV} \leq 10 \%$ is low variation (Zhang 2018).

\subsubsection{Geostatistical methods}

Geo-statistics can be adopted to study the spatial distribution of soil heavy metals, soil nutrients and soil moisture (Li et al. 2005; Pietrzykowski and Chodak 2014; Jing et al. 2018), where semi-variance function can be used to determine the spatial autocorrelation of variables, and Kriging interpolation method can also be used to simulate and estimate the regional content around the sampling point.

Semi-variance function, also known as variogram, is used to quantify the randomness and spatial structure of variables, below is the calculation formula:

$$
\gamma(h)=\frac{1}{2 \mathcal{N}(h)} \sum_{i=1}^{\mathcal{N}(h)}\left[\mathcal{Z}\left(\mathcal{X}_{i}\right)-\mathcal{Z}\left(\mathcal{X}_{i}+h\right)\right]^{2}(1)
$$

In this formula, $\mathrm{Y}(\mathrm{h})$ is the variogram; $\mathrm{h}$ is the spatial distance between two variables; $N(\mathrm{~h})$ is the number of sample point pairs; $\mathrm{Z}$ $\left(x_{i}\right)$ is the observation value of the spatial position point $x_{i} ; Z\left(x_{i}+h\right)$ is the observation value of the point h away from $x_{i}[i=1,2$, $\mathrm{N}(\mathrm{h})$ ]. The commonly used semi-variogram models include spherical model, Gaussian model and index model:

$$
\gamma(h)=\mathcal{C}_{0}+\mathcal{C}\left[1-e^{-\frac{h^{2}}{\alpha^{2}}}\right]
$$




$$
\begin{gathered}
\gamma(h)=\left\{\begin{array}{c}
\mathcal{C}_{0}+C\left[\frac{2}{3}\left(\frac{h}{\alpha}\right)-\frac{1}{2}\left(\frac{h}{\alpha}\right)^{2}\right] \\
\mathcal{C}_{0}+C
\end{array}\right. \\
\gamma(h)=\mathcal{C}_{0}+\mathcal{C}\left[1-e^{-\frac{h}{\alpha}}\right](4)
\end{gathered}
$$

In these formulas, $\mathrm{a}$ is the range; $\mathrm{C}_{0}$ is the nugget constant, which represents the variance caused by random error; $\mathrm{C}$ is the space structure value caused by systematic factors; $\mathrm{C}_{0}+\mathrm{C}$ is the abutment value, representing the total variance of variables; $\mathrm{C}_{0} /\left(\mathrm{C}_{0}+\mathrm{C}\right)$ is the spatial structure ratio. If $\mathrm{C}_{0} /\left(\mathrm{C}_{0}+\mathrm{C}\right)<25 \%$, it can be shown that the data has strong spatial correlation; when $25 \%<\mathrm{C}_{0} /\left(\mathrm{C}_{0}+\mathrm{C}\right)<$ $75 \%$, it can be shown that the data has medium spatial correlation; when $\mathrm{C}_{0} /\left(\mathrm{C}_{0}+\mathrm{C}\right)>75 \%$, it can be shown that the data has weak spatial correlation (Cambardella et al. 1994)).

The standard for selecting the semi-variance function model is that the closer the mean absolute error (MAE) and the root mean square error (RMSE) of the cross-check result is to 0 , the closer the regression fitting coefficient of determination $\mathrm{R}^{2}$ is to 1 , the higher is the accuracy of the model's simulation.

Kriging interpolation method is based on the spatial autocorrelation, using the original data of the regionalized variables and the structure of the variogram, with the adoption of linear, unbiased, and optimal interpolation methods for the unknown sampling points of the regionalized variables. The formula is as the following:

$$
\mathcal{Z}\left(x_{0}\right)=\sum_{i=1}^{n} \lambda_{i} \mathcal{Z}\left(x_{i}\right)(5)
$$

In this formula, $Z\left(x_{0}\right)$ is the value of the point to be estimated; $n$ is the number of sampling points; $Z\left(x_{i}\right)$ is the value of the $i$ sampling point; $\lambda_{\mathrm{i}}$ is a group of weight coefficients; $\sum \lambda_{\mathrm{i}}=1$; the selection of $\lambda_{\mathrm{i}}$ ensures that the estimation of $Z\left(x_{0}\right)$ is unbiased and the estimation variance is minimum.

\subsubsection{Principal Component Analysis method}

Principal component analysis (PCA) is a multivariate statistical analysis method that uses linear transformation to select a few important variables. After Kaiser Meyer Olkin (KMO) and sphericity test by Bartlett, the correlation analysis of vertical soil moisture in the study area was further adopted, and eventually the influencing factors of the vertical distribution of soil moisture were finalized (Zhang et al. 2017).

KMO test statistics are mainly used in factor analysis of multivariate statistics to check the correlation and partial correlation between variables with a value between $0-1$. The closer the statistical magnitude of KMO is to 1, the stronger the correlation between variables, and the weaker the partial correlation, the better the effect of factor analysis. Bartlett's sphere test is mainly used to test the distribution of data and the independence of various variables. In SPSS, if the test result shows Sig. $<0.05$, the data will show a spherical distribution. Common factor variance means that every variable can be represented by a common factor. The larger the extracted value is, the better the variable can be expressed by the common factor.

\section{Results}

\subsection{Statistical characteristics of soil moisture}

Descriptive statistics of $0-10 \mathrm{~m}$ soil moisture in CK, S1 and S2 regions were carried out (Table 1). It can be found from Table 1 that: (a) both the mean and median of the overall soil moisture of CK was higher than that of S1 and S2. Moreover, the mean of soil moisture at each depth level was basically close to the median value, indicating that the centralized distribution of data was not dominated by outliers; (b) the variation trend of SM in the vertical direction in different regions was basically the same. SM showed a downward trend above $2 \mathrm{~m}$, and reached the lowest value in the range of $1-2 \mathrm{~m}$ soil layer $(4.49 \%, 3.07 \%, 3.02 \%$, respectively). SM, however, increased from top to bottom with the increase of soil depth below $2 \mathrm{~m}$, and reached the maximum value in the range of 9 $10 \mathrm{~m}$ soil layer $(10.19 \%, 8.49 \%, 8.63 \%$, respectively). 
Table 1

Descriptive statistical results of SM

\begin{tabular}{|llllllllllllllll|l|}
\hline $\begin{array}{l}\text { Deep } \\
\begin{array}{l}\text { Soil } \\
(\mathbf{m})\end{array}\end{array}$ & CK & AVE & MIN & SD & CV & P & AVE & MIN & SD & CV & P & AVE & MIN & SD & CV & P \\
\hline $0-1$ & 5.44 & 5.19 & 0.73 & 13.37 & 0.2 & 4.55 & 4.39 & 1.12 & 24.7 & 0.2 & 4.83 & 4.48 & 1.14 & 23.6 & 0.09 \\
\hline $1-2$ & 4.49 & 4.47 & 0.95 & 21.21 & 0.2 & 3.07 & 2.72 & 1.5 & 48.71 & 0.2 & 3.02 & 3.05 & 0.68 & 22.47 & 0.2 \\
\hline $2-3$ & 6.53 & 5.90 & 2.09 & 31.99 & 0.2 & 3.78 & 3.85 & 1.86 & 49.2 & 0.2 & 4.12 & 4.18 & 0.84 & 20.32 & 0.2 \\
\hline $3-4$ & 4.81 & 4.32 & 0.87 & 18.17 & 0.13 & 4.35 & 3.63 & 2.57 & 59.05 & 0.12 & 3.90 & 3.52 & 1.05 & 26.93 & 0.06 \\
\hline $4-5$ & 3.80 & 4.08 & 1.4 & 36.78 & 0.2 & 4.97 & 5.06 & 2.37 & 47.75 & 0.2 & 4.13 & 3.69 & 1.03 & 25.02 & 0.13 \\
\hline $5-6$ & 5.89 & 5.09 & 2.05 & 34.83 & 0.2 & 5.45 & 5.40 & 2.05 & 37.6 & 0.2 & 4.45 & 4.78 & 1.62 & 36.39 & 0.2 \\
\hline $6-7$ & 4.94 & 4.63 & 1.63 & 33.1 & 0.11 & 4.62 & 4.58 & 1.36 & 29.55 & 0.14 & 7.58 & 8.33 & 2.46 & 32.5 & 0.05 \\
\hline $7-8$ & 8.71 & 9.59 & 2.13 & 24.43 & 0.2 & 6.79 & 7.12 & 2.45 & 36.15 & 0.2 & 8.26 & 7.84 & 2.9 & 35.14 & 0.2 \\
\hline $8-9$ & 10.77 & 10.68 & 1.9 & 17.65 & 0.17 & 7.73 & 6.12 & 5.06 & 65.53 & 0.2 & 7.12 & 6.26 & 2.26 & 31.68 & 0.06 \\
\hline $9-$ & 10.19 & 11.25 & 2.57 & 25.22 & 0.2 & 8.49 & 8.86 & 3.21 & 37.8 & 0.2 & 8.63 & 8.08 & 3.6 & 39.04 & 0.16 \\
\hline 10 & & & & & & & & & & & & & & \\
\hline
\end{tabular}

Meanwhile, according to Table 1, P > 0.05 for soil moisture of $0-10 \mathrm{~m}$ in the three regions, and there was no significant difference in $\mathrm{SM}$ among different depth of soil layers, indicating that the value of soil moisture in each depth passed the K-S normal distribution test. Overall comparison of the three regions showed that the CVs from large to small were S1, S2 and CK, with an average CV of $43.60 \%, 29.31 \%$ and $25.68 \%$ respectively, ranging from $24.7-65.53 \%, 20.32-39.04 \%$ and $13.37-36.78 \%$, indicating that the spatial variability of soil moisture in 1-year subsidence area was the highest. The above data show that there was no significant difference between the subsidence area and the control area, but there were still varying degrees of variability between different areas.

Compared with the CV of the same soil depth in different regions, the spatial variability of CK increased at the depth of 0-3m and 4$10 \mathrm{~m}$. The variability of $\mathrm{S} 1$ gradually increased in the range of $0-5 \mathrm{~m}$ and $7-9 \mathrm{~m}$, with the highest variability in $3-4 \mathrm{~m}$ and $8-9 \mathrm{~m}$. S2 showed an increasing trend as a whole, but the variability was in the middle of CK and S1, indicating that coal mining and other factors had a certain impact on the soil moisture in the two-year subsidence area. But as the subsidence stabilized, the area itself may complete certain self-repairs ( $\mathrm{Li}$ et al. 2012) so the degree of variation was relatively reduced. The above data show that the variation trend of subsidence area and control area was discrepant in different soil depths due to mining activities.

To sum up, the variation trend of soil moisture in the vertical direction in each area was basically similar. However, due to the different effects of coal mining activities and other factors on the soil at different depths, there were some differences in the variation degree. For example, the variation degrees of soil moisture in $0-1 \mathrm{~m}$ and $5-10 \mathrm{~m}$ in the control area were significantly lower than that in the subsidence area, while there was no consistent rule in the $2-5 \mathrm{~m}$ soil moisture variation, indicating that the surface subsidence increased the variation degree of soil moisture; with the subsidence entering the stable stage, the variation degree was relatively decreased, but in $0-1 \mathrm{~m}$ soil surface layer and $5-10 \mathrm{~m}$ soil deep layer the variation degree was still greater than that in the control area.

\subsection{Spatial structure change of soil moisture}

Table 2 shows the best-fitting models of CK, S1 and S2 in $0-10 \mathrm{~m}$ soil layers. $\mathrm{C}_{0}$ is the variation caused by experimental errors and the microdomain structure smaller than the actual sampling scale, reflecting the size of random variation C (Cambardella et al. 1994). It can be found from Table 3 that the vertical comparison of $\mathrm{C}_{0}$ value in the subsidence area showed that the random variation of deep soil was larger than that of surface soil, which may be caused by the difficulty of deep soil sampling. 
Table 2

Spatial variation models of SM

\begin{tabular}{|c|c|c|c|c|c|c|}
\hline Region & Deep Soil(m) & Model & $\mathrm{C}_{0}$ & $C_{0}+C$ & $\begin{array}{l}\text { Range } \\
\text { (m) }\end{array}$ & $\mathrm{C}_{0} /\left(\mathrm{C}_{0}+\mathrm{C}\right)$ \\
\hline \multirow[t]{10}{*}{ CK } & $0-1$ & Gaussian & 0.005 & 0.160 & 253.468 & 3.13 \\
\hline & $1-2$ & Gaussian & 0.005 & 0.327 & 238.971 & 1.53 \\
\hline & $2-3$ & Gaussian & 0.004 & 4.411 & 263.565 & 0.09 \\
\hline & $3-4$ & Gaussian & 0.061 & 0.138 & 450.000 & 44.20 \\
\hline & $4-5$ & Index & 0.552 & 1.114 & 213.438 & 49.55 \\
\hline & $5-6$ & Index & 0.450 & 0.261 & 450.000 & 0.00 \\
\hline & $6-7$ & Gaussian & 0.121 & 0.423 & 298.380 & 0.00 \\
\hline & $7-8$ & Gaussian & 0.231 & 0.297 & 450.000 & 10.44 \\
\hline & $8-9$ & Gaussian & 0.340 & 0.808 & 288.841 & 0.00 \\
\hline & $9-10$ & Spherical & 0.421 & 0.857 & 300.000 & 0.00 \\
\hline \multirow[t]{10}{*}{ S1 } & $0-1$ & Gaussian & 0.344 & 0.682 & 266.497 & 50.44 \\
\hline & $1-2$ & Gaussian & 0.107 & 1.582 & 208.319 & 6.76 \\
\hline & $2-3$ & Gaussian & 0.003 & 2.882 & 200.261 & 0.10 \\
\hline & $3-4$ & Index & 0.436 & 4.029 & 294.072 & 10.82 \\
\hline & $4-5$ & Gaussian & 1.340 & 4.978 & 475.805 & 26.92 \\
\hline & $5-6$ & Gaussian & 1.683 & 2.389 & 252.140 & 70.45 \\
\hline & $6-7$ & Index & 0.895 & 0.895 & 797.141 & 100.00 \\
\hline & $7-8$ & Gaussian & 2.315 & 3.100 & 421.271 & 74.68 \\
\hline & $8-9$ & Gaussian & 8.232 & 15.336 & 797.141 & 53.68 \\
\hline & $9-10$ & Index & 4.079 & 4.08 & 797.14 & 100.00 \\
\hline \multirow[t]{10}{*}{ S2 } & $0-1$ & Gaussian & 0.273 & 0.896 & 452.761 & 30.47 \\
\hline & $1-2$ & Gaussian & 0.049 & 0.337 & 252.140 & 14.54 \\
\hline & $2-3$ & Gaussian & 0.000 & 0.694 & 299.757 & 0.00 \\
\hline & $3-4$ & Index & 0.000 & 0.500 & 195.877 & 0.00 \\
\hline & $4-5$ & Gaussian & 0.005 & 0.515 & 173.878 & 0.97 \\
\hline & $5-6$ & Index & 1.000 & 1.208 & 152.896 & 82.78 \\
\hline & $6-7$ & Gaussian & 2.247 & 3.882 & 679.738 & 57.88 \\
\hline & $7-8$ & Gaussian & 3.104 & 3.503 & 722.239 & 88.61 \\
\hline & $8-9$ & Gaussian & 1.210 & 1.722 & 183.909 & 70.27 \\
\hline & $9-10$ & Gaussian & 3.874 & 4.506 & 252.14 & 85.97 \\
\hline
\end{tabular}


Table 3

The principal component analysis of SM

\begin{tabular}{|c|c|c|c|c|c|c|c|c|c|}
\hline \multirow[t]{2}{*}{ Component } & \multicolumn{3}{|c|}{ Initial Eigenvalue } & \multicolumn{3}{|c|}{ Extract the Load Sum of Squares } & \multicolumn{3}{|c|}{$\begin{array}{l}\text { Sum of the Square of the Rotating } \\
\text { Load }\end{array}$} \\
\hline & total & $\begin{array}{l}\text { variance } \\
\text { percentage }\end{array}$ & $\begin{array}{l}\text { accumulate } \\
\%\end{array}$ & total & $\begin{array}{l}\text { variance } \\
\text { percentage }\end{array}$ & $\begin{array}{l}\text { accumulate } \\
\%\end{array}$ & total & $\begin{array}{l}\text { variance } \\
\text { percentage }\end{array}$ & $\begin{array}{l}\text { accumulate } \\
\%\end{array}$ \\
\hline $0-1 \mathrm{~m}(\mathrm{x} 1)$ & 4.188 & 41.879 & 41.879 & 4.188 & 41.879 & 41.879 & 3.112 & 31.116 & 31.116 \\
\hline $1-2 m(x 2)$ & 1.939 & 19.387 & 61.266 & 1.939 & 19.387 & 61.266 & 2.960 & 29.595 & 60.711 \\
\hline $2-3 m(x 3)$ & 1.484 & 14.838 & 76.104 & 1.484 & 14.838 & 76.104 & 1.539 & 15.392 & 76.104 \\
\hline $3-4 m(x 4)$ & 0.960 & 9.605 & 85.709 & & & & & & \\
\hline $4-5 m(x 5)$ & 0.583 & 5.830 & 91.539 & & & & & & \\
\hline $5-6 m(\times 6)$ & 0.376 & 3.756 & 95.295 & & & & & & \\
\hline $6-7 m(x 7)$ & 0.267 & 2.674 & 97.969 & & & & & & \\
\hline $7-8 m(x 8)$ & 0.164 & 1.641 & 99.610 & & & & & & \\
\hline $8-9 m(\times 9)$ & 0.037 & 0.365 & 99.975 & & & & & & \\
\hline $9-10 m(x 10)$ & 0.003 & 0.025 & 100.000 & & & & & & \\
\hline
\end{tabular}

Table 4 The rotated matrix principal component analysis of SM

\begin{tabular}{llll} 
Deep Soil $(\mathrm{m})$ & \multicolumn{3}{l}{ Factor Load After Rotation } \\
\cline { 2 - 4 } & Y1 & Y2 & Y3 \\
\hline 0-1m(x1) & 0.354 & 0.205 & -0.797 \\
\hline $1-2 m(x 2)$ & 0.278 & 0.920 & -0.200 \\
\hline 2-3m(x3) & 0.340 & 0.905 & -0.072 \\
\hline 3-4m(x4) & -0.052 & 0.919 & 0.063 \\
\hline 4-5m(x5) & 0.246 & 0.755 & 0.000 \\
\hline 5-6m(x6) & 0.694 & 0.197 & 0.142 \\
\hline 6-7m(x7) & 0.817 & -0.079 & 0.112 \\
\hline 7-8m(x8) & 0.611 & 0.421 & 0.411 \\
\hline 8-9m(x9) & 0.804 & -0.026 & -0.161 \\
\hline 9-10m(x10) & 0.820 & 0.276 & -0.238
\end{tabular}

According to $\mathrm{C}_{0}+\mathrm{C}$, all soil layers in the control area were lower than those in the subsidence area, which indicated that the variation of soil moisture in the control area was small within the range of variation. However, considering the variation trend of $\mathrm{C}_{0}$ in the three areas, it is found that the $\mathrm{C}$ value (structural variance, representing the variation of non-random causes in the subsidence area) at 0 $1 \mathrm{~m}$ and 5-10m was relatively larger than that in the CK, which indicated that the structural factors including climate, coal mining subsidence, and soil texture have greater impact on the subsidence area.

The spatial structure ratio $\mathrm{C}_{0} /\left(\mathrm{C}_{0}+\mathrm{C}\right)$ represents the proportion of system variation in the total variation. According to the standard by Cambardella et al. (1994), CK exhibited a strong spatial autocorrelation between 0-3m and 5-10m $\left(\mathrm{C}_{0} /\left(\mathrm{C}_{0}+\mathrm{C}\right)<25 \%\right)$, with moderate spatial autocorrelation in $3-5 \mathrm{~m}\left(25 \%<\mathrm{C}_{0} /\left(\mathrm{C}_{0}+\mathrm{C}\right)<75 \%\right)$; $\mathrm{S} 1$ had strong spatial correlation only in $1-4 \mathrm{~m}$ while moderate or weak spatial correlation in other depths; $\mathrm{S} 2$ had a strong spatial correlation only at $1-5 \mathrm{~m}$ while moderate or weak spatial correlation in other depths; especially at a depth of $5-10 \mathrm{~m}$, the $\mathrm{C}_{0} /\left(\mathrm{C}_{0}+\mathrm{C}\right)$ of 1 -year and 2-year subsidence areas were larger than $50 \%$, and the 
degree of spatial variation was high. In conclusion, the soil moisture in the one-year subsidence area and 2-year subsidence area showed strong or moderate spatial variability on the surface of soil (0-1m) and deep soil (5-10m), which was consistent with the variation trend in the classical statistical results. Meanwhile, it was shown that the contribution of random factors to the spatial distribution of soil surface and deep layer was relatively small, and the spatial variation is mainly caused by structural factors.

Based on the above results, it is found that the overall variation degree of subsidence area was higher than that of the control area, and the variation caused by structural factors such as climate, mining subsidence and soil texture has a greater impact on the subsidence area, especially the spatial variability of surface and deep soil.

Use cross-check to verify the accuracy of the interpolation results in the three regions, and calculate the MAE, RMSE, and $\mathrm{R}^{2}$ between the predicted value and the true value (Fig. 3). As can be seen from Fig. 3, MAE and RMSE in S1 increased by $22.77 \%$ and $19.62 \%$ respectively compared with the CK; in S2, MAE and RMSE increased by $1.76 \%$ and $6.64 \%$ respectively compared with the CK, but decreased by $17.11 \%$ and $10.85 \%$ compared with the $\mathrm{S} 1$. It showed that the Kriging interpolation accuracy of the control area was generally higher than that of the subsidence area, and the interpolation accuracy of the subsidence area was the lowest in 1 years, that is, as the spatial variability of soil moisture increases, the accuracy of Kriging interpolation decreases. $\mathrm{R}^{2}$ in the CK, S1 and S2 are $0.76,0.59$ and 0.71 respectively, which is close to Zou's (2014) spatial interpolation results of soil moisture in Shendong mining area reflecting that the greater the spatial variability of soil moisture, the lower the fitting accuracy between the predicted value and the measured value.

\subsection{Spatial distribution of soil moisture}

From the above analysis, it can be seen in Fig. 4 that soil moisture has great spatial variability in 0-1m and 5-10m. Therefore, Kriging interpolation method was used to draw the spatial distribution map of soil moisture in CK, S1 and S2 layers $(0-1 \mathrm{~m}, 5-6 \mathrm{~m}$ and $9-10 \mathrm{~m})$.

Comparing the interpolation results of CK, S1 and S2 in 0-1m, 5-6m and 9-10m, it was found that there were no significant spatial variability in $0-1 \mathrm{~m}$, and there were one low value area and two high value areas of SM. The low value area was located in the oneyear subsidence area, while the high value area was located in the control area and the two-year subsidence area. This is mainly because the control area was not affected by the ground fissures caused by coal mining, while the two-year subsidence area was gradually stable so that the soil moisture was restored. At 5-6m, the high value area was mainly located in the control area and 1year subsidence area, but the soil moisture distribution in the subsidence area had poor spatial continuity so as to indicate that the subsidence caused by coal mining had a certain impact on the soil moisture distribution. In $9-10 \mathrm{~m}$, the distribution of high value and low value areas of soil moisture were similar to that of $0-1 \mathrm{~m}$ soil layer. The high value area was mainly located in the northwest of the control area and the 2-year subsidence area. However, the low value area and the high value area in the 2-year subsidence area had poor spatial continuity, which referred to high spatial variability. On the whole, the distribution of soil moisture is that the high value area was located in the control area, followed by the 2-year subsidence area and the 1-year subsidence area, which proves that the surface subsidence has a greater impact on the soil moisture; the areas with obvious spatial variability of soil moisture were mainly in the subsidence area, especially in the deep soil, whose reason is the control area has not been mined. The surface subsidence and ground fissures caused by the disturbance of coal mining changed the soil structure and the water transport channel, so the soil moisture decreased and the spatial variability increased.

The results of soil water interpolation of CK, S1 and S2 in 0-1m, 5-6m and 9-10m were compared vertically, and then it was found that the soil moisture in the three regions decreased initially and then increased, which was consistent with the changing trend of water in the results of classic statistical analysis. At the same time, it can be seen that in CK area, there was weak spatial variability in each depth, and the vertical distribution of soil water had obvious regularity, showing a decreasing trend from northwest to southeast; in S1 and S2 areas, the soil moisture in each depth layer was less than that in CK area, and there was no obvious regularity in the vertical distribution, and the variation degree of soil moisture in each depth layer was also larger than that in the CK area. The reason is that the coal mining collapse caused the soil layer in the subsidence area to be vertically inverted and reorganized, so that it caused changes in soil texture, bulk density, porosity, and other physical properties of the soil, resulting in a significant decrease in the subsidence area in soil moisture compared to that in the control area. Moreover, it was also shown a strong variability existed in the spatial distribution.

By comparing the soil water distribution in three regions vertically and horizontally, it is found that the results of Kriging interpolation are basically consistent with the results of classical statistics and model fitting. The water content in the control area is higher than 
that in the subsidence area, while the variation degree of subsidence area is higher than that of the control area. The main reason may be that the surface subsidence and ground fracture caused by mining disturbance changed the soil structure and soil physical properties, Then, it affected the water migration channel, which led to the decrease of soil water and the increase of spatial variability.

\section{Discussion}

\subsection{Analysis of influence factors}

It can be seen from 2.1 and 2.2 that the spatial variability of soil moisture in 1-year subsidence area was relatively high. Therefore, the principal component analysis of 0-10m soil moisture in 1-year subsidence area was used to study the main influencing factors. The results are shown in Table 3 and table 4. In this study, three principal component factors $Y 1, Y 2$ and $Y 3$ were obtained, and their corresponding variance contribution rates were $41.879 \%, 19.387 \%$ and $14.838 \%$ respectively. The total cumulative variance rate was $76.104 \%$.

From the matrix after rotation, the main influencing factors of the vertical distribution of soil moisture in 1-year subsidence area can be found that the vertical distribution of $0-1 \mathrm{~m}$ soil moisture is mainly affected by factor $\mathrm{Y} 3$. The factor load is -0.797 , which may be surface factors such as vertical cracks and subsidence (Guo et al. 2019), evaporation (Xu et al. 2018) and vegetation cover caused by coal mining subsidence. The vertical distribution of soil moisture at $5-10 \mathrm{~m}$ was mainly affected by the factor $\mathrm{Y} 1$, possibly due to underground factors such as changes in the microstructure of soil pores caused by rock and soil deformation, to changes in groundwater level caused by disturbances in coal mining (Xu et al. 2018), and their factor loads were respectively $0.694,0.817$, $0.611,0.804,0.820$. The factors $\mathrm{Y} 1$ and $\mathrm{Y} 3$ had little effect on the vertical distribution of soil water in the range of $1-5 \mathrm{~m}$, and were mainly affected by factor $\mathrm{Y} 2$, which might be the water holding capacity and infiltration capacity of the soil itself, and their factor loads were $0.920,0.905,0.919$ and 0.755 , respectively. Considering the above factors, it can be found that no matter ground fractures, subsidence, deformation of rock and soil layer, or groundwater change, it is ultimately because the coal mining activities change the soil porosity and texture. Those activities form the priority channel of water migration, which affects the distribution of water and its circulation migration channel.

\subsection{Effect of coal mining on soil moisture}

The schematic diagram of the effect of coal mining on soil moisture is shown in Fig. 5 . The underground coal mining makes the underground goaf and surface collapse. The tensile action in the process of collapse develops a large number of surface fissures (fissures) resulting in changes of the original texture and structure of the soil and the presence of preferential flow. Therefore, the hydraulic conductivity of the soil as well as the evaporation area and intensity of soil water are increased. At the same time, the field water holding capacity, the water holding capacity of the whole aerated zone, and the soil moisture content is reduced. As a common form of soil water transport and a sign of soil water movement from homogeneous to heterogeneous, preferential flow is the rapid and non-equilibrium seepage flow of water in the soil. Preferential flow can reduce the effectiveness of water and nutrients, threaten groundwater, and cause natural disasters such as avalanches, landslides and mudslides (Meirvenne et al. 2003). As a common phenomenon in soil, fissures have complex effects on the generation and process of preferential flow. When the cracks are small, the rainfall first needs to supplement the moisture loss of the upper soil, and then infiltrates downward; when the cracks are large, the rainfall infiltration mode also changes from "piston" infiltration in the non-collapse area to the "shortcut" one. The surface water infiltrates directly along the large cracks, and directly connects with the groundwater and mine water, changing the original soil moisture circulation path, which is the generation of preferential flow. At the same time, the fissures increase the surface area of water infiltration, which leads to an increase in the transport speed of water and solutes (Ma 2007), resulting in changes in soil moisture. Therefore, the soil fissures caused by coal mining will lead to the production of preferential flow. The study on the characteristics of soil priority flow in Shen Dong subsidence area shows that the soil preferential flow in coal mining subsidence area mainly includes the soil macropore flow. The soil water infiltration process in the studied area has the characteristics of nonequilibrium. The steady rate of infiltration and outflow of the soil layer with preferential flow is greater than that of the soil layer with uniform flow (Su 2018). Therefore, it can be found that the subsidence caused by coal mining collapse as well as the soil priority flow caused by cracks are reasons for the change of soil surface water. 
In addition, soil moisture is also affected by its water holding capacity, infiltration capacity and other factors, which are closely related to its bulk density, porosity, texture and other soil properties. The disturbing effect of coal mining on the soil is not only reflected in the surface or a certain level, but from top to bottom, it will be directly or indirectly disturbed by coal mining. In this regard, due to the indirect influence of surface subsidence or ground fissures, the soil properties of the middle soil have changed to a certain extent, such as the increase of porosity and the decrease of bulk density. Those changes will inevitably affect the water holding capacity and infiltration capacity of the soil, thus affecting the movement of soil water. The preferential flow mentioned above initially refers to the phenomenon of water flowing through macropores and bypassing the soil matrix to move down rapidly. Therefore, the change of soil moisture in the middle is caused by the macropores resulted from the disturbance of coal mining, that is preferential flow, which changes the channel of soil water movement. In Suning's research, it is pointed out that as the depth of the soil increases, the spatial differentiation and variation of the preferential flow of the soil in the coal mining subsidence area continues to increase, and the spatial morphology of the flow in the area where preferential flow occurs becomes more complex (Su 2018).

At the same time, after the underground coal seam is mined out or the ore body aquifer is discharged, the stress equilibrium of the rock mass around the goaf changes. The changes will inevitably cause the deformation, breakage and movement of the rock layer (Zhu 2017), and then change the microstructure of soil pores (i.e., produce cracks), so as to affect the movement of soil water. In addition, due to coal mining, the groundwater level in the underground part of mining and the surrounding area drops, resulting in a large amount of water loss of the surface soil and soil volume shrinkage. Finally, the fissure preferential flow is formed (Li et al. 2015) and affects the movement and distribution of soil water. The depth of this fissure is generally above the phreatic water level, or in the entire soil aerated zone. Its scale and distribution are often closely related to the scale of underground engineering, mining technology and mining speed, the physical and mechanical properties of the land and hydraulic power, as well as to the soil moisture content of the soil in the tensile deformation stage (Cheng 2016). To sum up, the changes of soil pore microstructure and groundwater level caused by the deformation of rock and soil caused by coal mining will lead to the formation of preferential flow of soil fissure and change the soil water transport channel. Moreover, the mining scale and intensity are different in various areas, and the spatial variation of soil water will be different.

Considering the above conclusions, it can be inferred that (Fig. 5): the collapse and cracks caused by underground coal mining have changed the surface soil texture to a certain extent and caused preferential flow, which in turn affected the evaporation, infiltration and migration of soil moisture. However, due to the limited influence range of collapse and cracks, although the average value of soil water content in the subsidence area has decreased, there is no consistent change law in the overall spatial distribution, and an increase in spatial variability is shown. In addition, the changes in soil hydraulic properties caused by the indirect influence of coal mining disturbances, the changes in the microstructure of soil pores caused by the deformation of rock and soil caused by coal mining as well as the fluctuations of groundwater level also have significant effects on the moisture in the deep unsaturated zone of the soil, so that the disturbance spatial variability is enhanced.

\section{Conclusions}

Using the methods of classical statistics and multi-dimensional geo-statistics, this study reveals that coal mining leads to geological subsidence and surface deformation, and finally leads to the change of soil layer structure, so that the original soil moisture is distributed in the form of preferential flow, showing the law of increasing the variability of regional soil moisture content.

The increase of regional soil moisture content variability is mainly due to the collapse caused by coal mining, which leads to the deformation of surface soil and the change of soil porosity and bulk density. The variability of shape variable and soil moisture content caused by coal mining needs to be further studied.

Analyzing the change of soil moisture content in different coal mining periods in the region from the perspective of variability can better explain the impact of coal mining on soil and ecology, and it is more accurate to analyze the impact compared with the change of traditional absolute value of moisture content. In the next step, the variation of soil moisture content and the tolerance of surface vegetation will be used to further reveal the impact of coal mining subsidence on surface ecosystem.

\section{Declarations}

Page $11 / 16$ 


\section{Acknowledgements}

This work was funded by the National Key Research and Development Program of China (2018YFC0406404), Yue Qi Young Scholar Project, China University of Mining \& Technology, Beijing (2019QN08), and the Research on Ecological Restoration and Protection of Coal Base in Arid Eco-fragile Region (GJNY2030XDXM-19-03.2).

Conflict of interest: The authors declare no competing interests.

\section{References}

1. Bi YL, Zou H, Peng C. et al. (2014) Effects of mining subsidence on soil water movement in sandy area. Journal of China Coal Society 39:490-496.

2. Cambardella CA, Moorman TB, Novak JM, et al. (1994) Field-scale variability of soil properties in central lowa soils. Soil Science Society of America Journal 58(5):1501-1511. https://doi.org/10.2136/sssaj1994.03615995005800050033x

3. Cheng FK (2016) Simulation study on soil crack preferential flow and its impacts on soil and water loss in coal mining subsidence area. Dissertation, Anhui University of Science \& Technology.

4. Cheng JX, Nie XJ, Liu CH (2014) Spatial variation of soil organic carbon in coal-mining subsidence areas. Journal of China Coal Society 39:2495-2500.

5. Dougill AD, Heathwaite AL, Thomas DSG (1998) Soil water movement and nutrient cycling in semi-arid rangeland: Vegetation change and system resilience. Hydrological Processes 12:443-459. https://doi.org/10.1002/(SICI)1099-

1085(19980315)12:3<443::AID-HYP582>3.0.CO,2-N

6. Guo QL, Ma ZH, Su N (2019) Effects of cracks in coal mining subsidence area on soil moisture content in Shen fu-Dongsheng coalfield. Science of Soil and Water Conservation 17:109-116.

7. Jing Z, Wang J, Zhu Y, et al. (2018) Effects of land subsidence resulted from coal mining on soil nutrient distributions in a loess area of China. Journal of Cleaner Production 177:350-361.

8. Li LL, Yi YL, Ling GX, et al. (2005) Utilization of geo-statistics in soil spatial variability. Chinese Journal of Soil Science 02: 265268.

9. Li QS, He AM, Gao GZ (2012) Research on surface ecological self-repair under modern coal mining technology in Shen Dong mining area. Coal Engineering 12:120-122.

10. Li SJ, Zhou DX, Li JM (2001) Effects of different nitrogen fertilizer amounts on wheat yield and nitrogen distribution and utilization under limited water irrigation. Acta Agricultura Boreali-Sinica 03:86-91.

11. Li WJ, Zhang ZY, Wang C (2015) Propagation and closure law of desiccation cracks of loamy clay during cyclic drying-wetting process. Transactions of the Chinese Society of Agricultural Engineering (Transactions of the CSAE) 31:126-132.

12. Liu ZR, Yan L, He X, Bao LY, Liu GJ (2014) Effects of mining subsidence on physical and chemical properties of soil in the subsided land of the Daliuta Mining Area. Journal of Arid Land Resources and Environment 28:133-138.

13. Liu, Y., Wu, L.X., Yu, H.,2016. Effect of underground coal mining on land surface soil moisture in desert mining area. Coal Science and Technology 44:197-202.

14. Ma J (2007) Preferential flow and stability analysis method for fissure clay slopes. Dissertation, Graduate School of Chinese Academy of Sciences (Wuhan Institute of Geotechnical Mechanics).

15. Ma K, Yang L (2019) Vertical variation characteristics of soil moisture near stepped ground fissures in Yu Shen fu mining area. Journal of Green Science and Technology 04:158-159.

16. Meirvenne MV, Maes K, Hofman G (2003) Three-dimensional variability of soil nitrate-nitrogen in an agricultural field. Biology \& Fertility of Soils 37:147-153. https://doi.org/10.1007/s00374-003-0581-x

17. Pietrzykowski M, Chodak M (2014) Near infrared spectroscopy-A tool for chemical properties and organic matter assessment of afforested mine soils. Ecological Engineering 62:115-122. https://doi.org/10.1016/j.ecoleng.2013.10.025

18. Su N (2018) Study on the characteristics of soil preferential flow in the Shenfu Dongsheng coal mining subsidence area. Dissertation, Henan Polytechnic University.

Page $12 / 16$ 
19. Wang J (2017) Study on ecological damage characteristics and environmental restoration of subsidence areas in Shen Dong Coalfield. Dissertation, Inner Mongolia Agricultural University.

20. Wang J, Gao Y, Wei JS (2006) Influence of mining subsidence on physical and chemical properties of soil in windy desert area. Journal of Soil and Water Conservation 05:52-55.

21. Wang JL, Kang JR, Hu JS (2011) Influential research of mining ground fissures on water and soil resources. Shanxi Coal 31: 2730.

22. Wang L, Wei SP, Wang QJ (2008) Effect of coal exploitation on groundwater and vegetation in the Yushenfu Coal Mine. Journal of China Coal Society 33:1408-1414.

23. Wang XZ (2015) Strategic consideration of China coal industry development during energy revolution and new normal of economic development. China National Coal Association 41: 5-8.

24. Wei JS, He X, Hu CY (2006) Influence of ground collapse caused by coal mining activities on the water characteristics of sandy soil in arid and semi-arid area. Journal of Arid Land Resources and Environment 05: 84-88.

25. Wu L, Tian JF, Tang Y (2019) Effects of collapse-fissure on soil moisture in arid and semi-arid mining areas. South-to-North Water Transfers and Water Science \& Technology 17:115-120.

26. Wu QY, Feng ZW, Hu ZQ (2020) Influence of dynamic variation of ground cracks on soil water content in ecological-fragile coal mining areas. Coal Science and Technology 48:148-155.

27. Xi JP (2019) Speech at the symposium on ecological protection and high-quality development of the Yellow River Basin. Water Resources Development and management 11:1-4.

28. Xu CC, Xu GJ, Ma SZ (2018) Study on the water characteristics and influencing factors of unsaturated zone in mining subsidence area in plain area. Ground Water 40:9-11+95.

29. Zhang B, Gao ZL, Wang D (2012) Discussion on the eco-economic development pattern in eco-fragile region of drought and desertification. Ecological Economy 02:67-75.

30. Zhang K (2018) Temporal and Spatial Distribution and Risk Assessment of Heavy Metal Pollution in Modern Coal Chemical Plant. Dissertation, China University of Mining \& Technology, Beijing.

31. Zhang K, Yang JJ, Bai L (2017) The characteristics and source apportionment of heavy metal pollution in the soil at a coal chemical industry area in northwest China. Journal of Mining Science and Technology 2:191-198.

32. Zhang YX, Bi YL, Chen SL (2015) Effects of subsidence fracture caused by coal-mining on soil moisture content in semi-arid windy desert area. Environmental Science \& Technology 38:11-14.

33. Zhao HM (2006) Research of soil water distribution and dynamic characteristics under the coal mining condition. Dissertation, Chinese Academy of Geological Sciences.

34. Zhao HM, Zhang FW, Song YX (2010) Spatial variation of soil moisture content in mining subsidence areas of Da Liu ta, Shen mu County, Shanxi Province. Journal of Geo-Information Science 12:753-760.

35. Zhu W (2017) Study on movement and deformation law of overlying strata caused by mine of soft rock working face. Dissertation, Anhui University of Science and Technology.

36. Zou H, Bi YL, Zhu CW (2014) Effect of mining subsidence on soil moisture dynamic changes of sandy land. Journal of China University of Mining \& Technology (Social Science) 43:496-501.

\section{Figures}




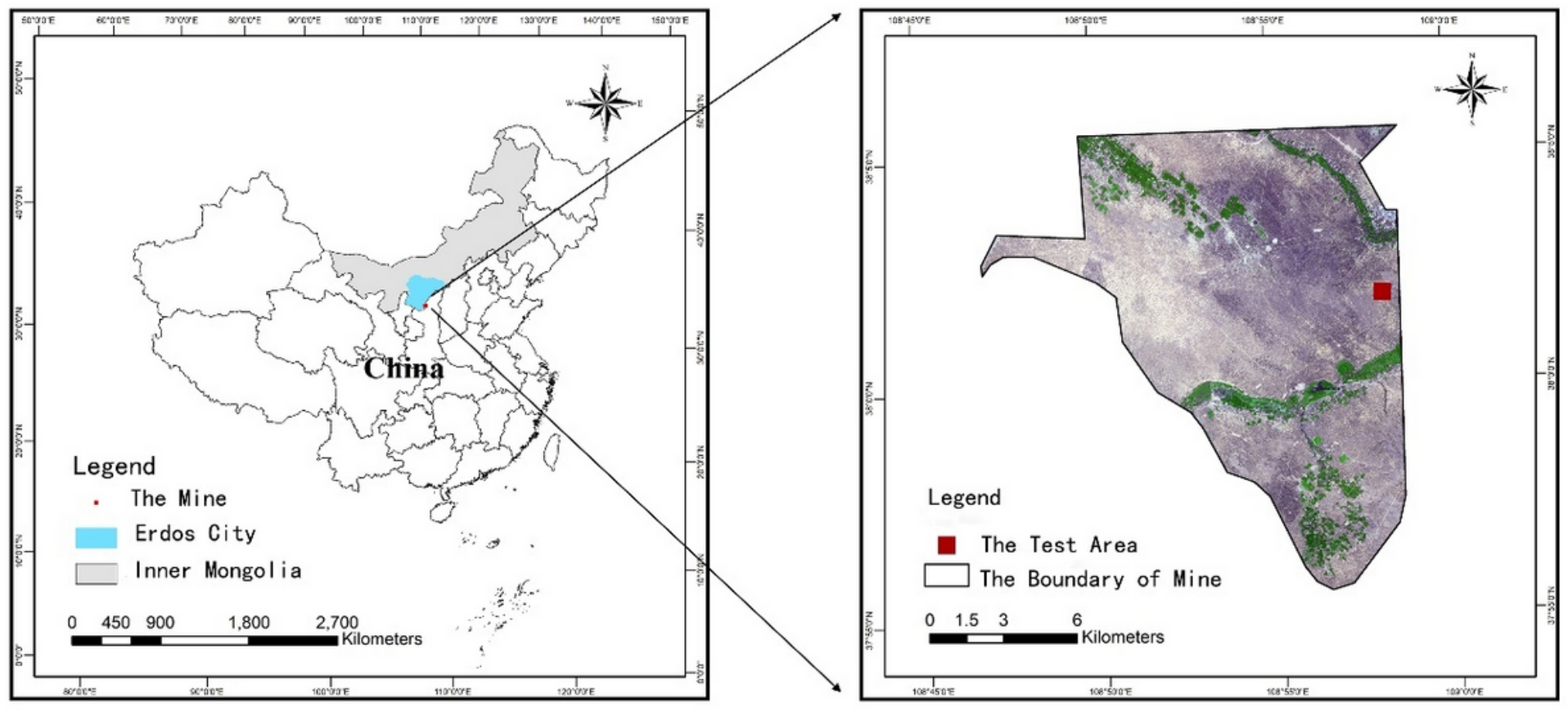

Figure 1

Schematic diagram of geographic location for study region

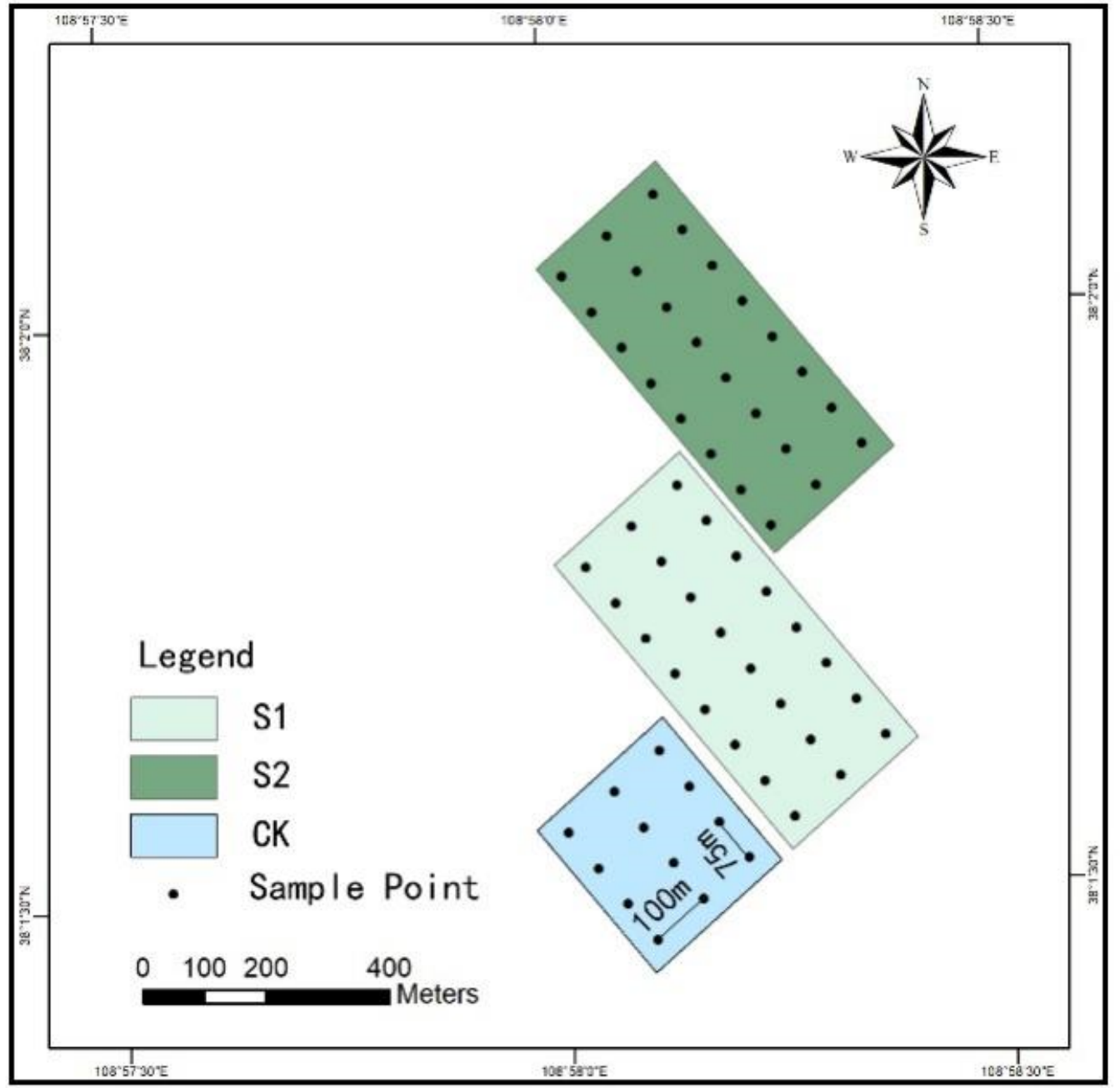

Figure 2 

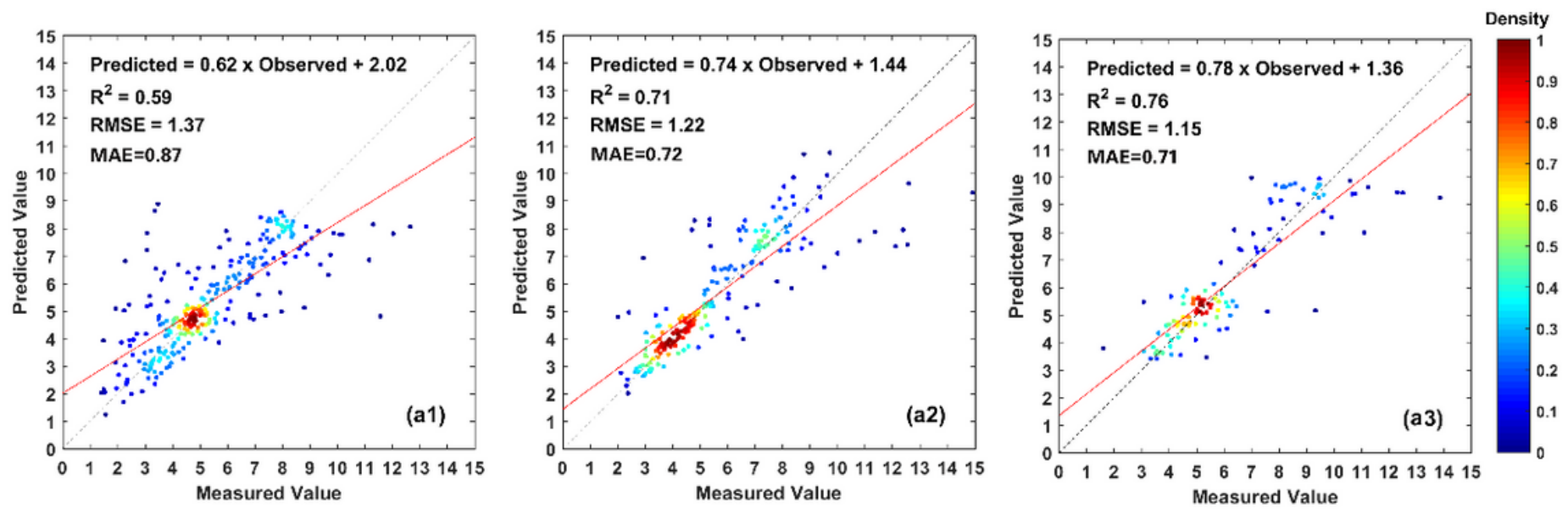

Figure 3

Crosscheck charts: a1.S1, a2.S2, a3. CK
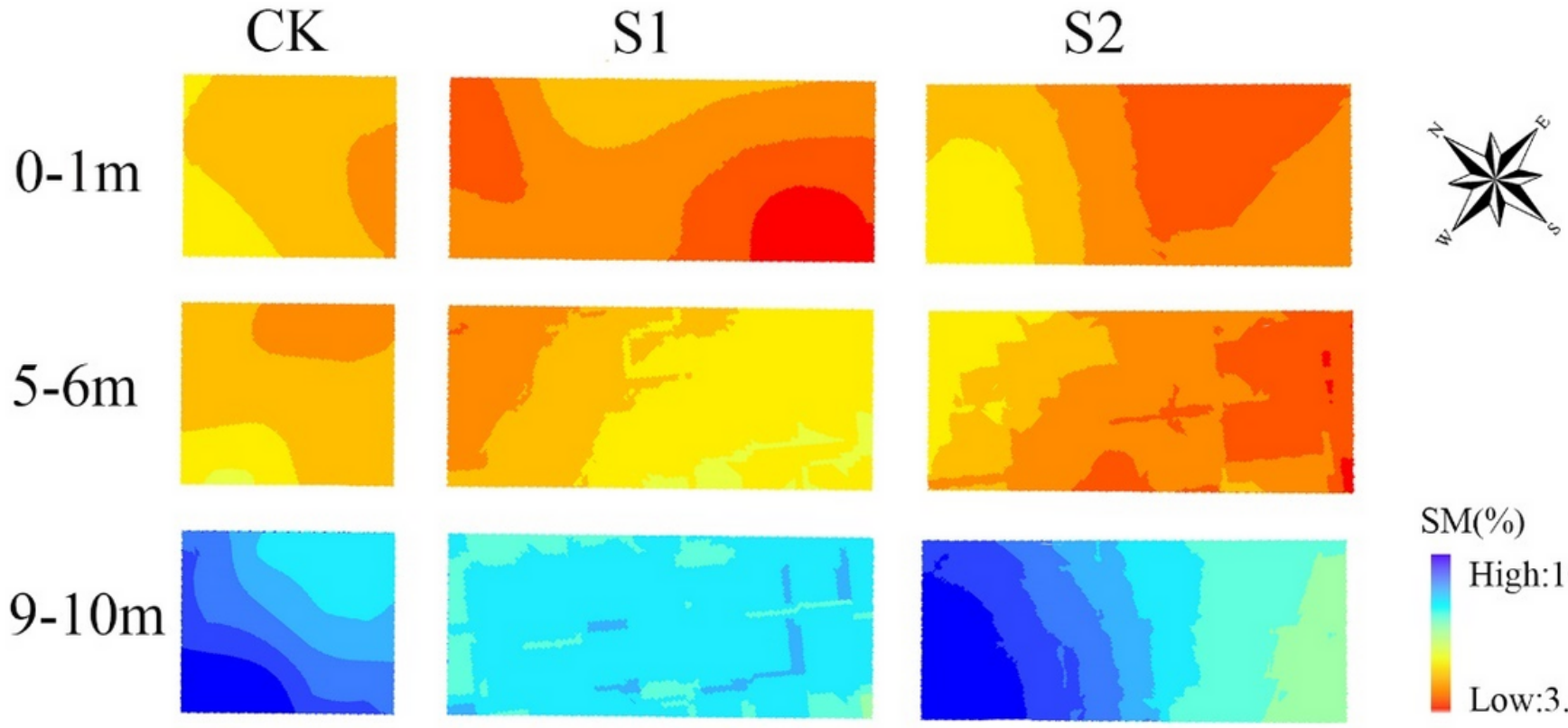

$\operatorname{SM}(\%)$

High:10.7

Low:3.7

\section{Figure 4}

Spatial variability of soil moisture (resolution ratio $2 m \star 2 m$ ) 


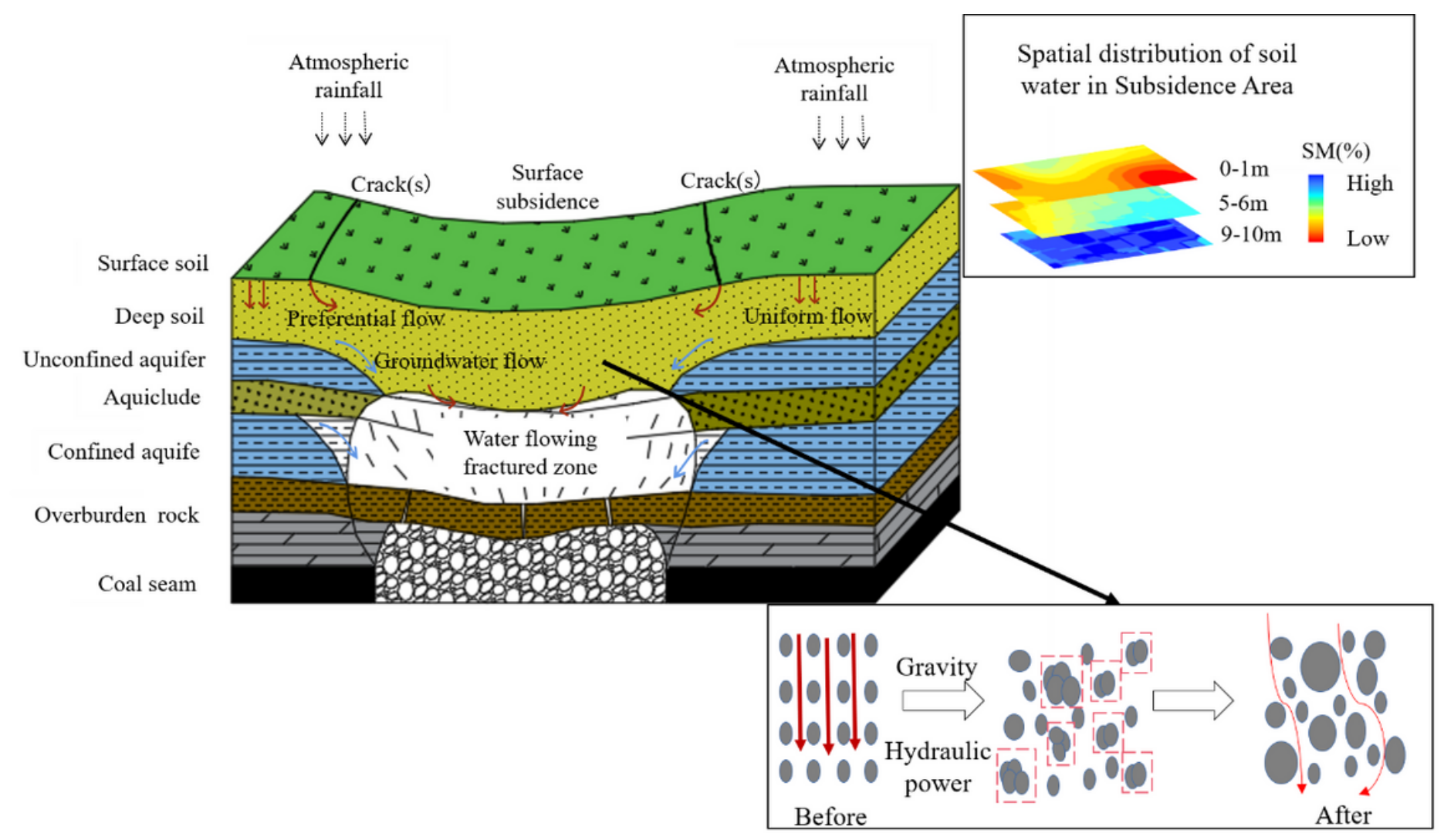

\section{Figure 5}

Schematic diagram of spatial variation of soil moisture in coal mining subsidence area 